\section{PEER-TO-PEER ESPORTS \\ SANCTIONING ORGANIZATION}

\section{BECKY HARRIS, ALEX A. IGELMAN, AND MICHAEL POLLOCK}

Becky Harris is currently a Distinguished Fellow in Gaming and Leadership with the University of Nevada, Las Vegas (UNLV) International Gaming Institute (IGI) in Las Vegas, Nevada, USA. She previously served as the chair of the $\mathrm{Ne}$ vada Gaming Control Board and as a Nevada state senator.

Alex A. Igelman, LLB, is a gaming and esports lawyer intimately involved in the regulation of online gambling, and the founder of Esports Capital Corp. in Toronto, Canada.

Michael Pollock is the managing director of Spectrum Gaming Group in Pennsylvania, USA.

\section{INTRODUCTION}

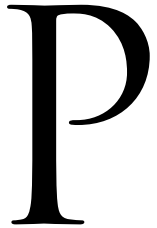

eer-to-peer play is hardly a new concept. It is simply a system which provides the necessary means for competition to take place. Competitions may vary and may involve providing the necessary physical or virtual space to enable the competition to take place, supplying the equipment to facilitate the activity, arranging for both the space and the equipment or neither.

Peer-to-peer play operators would be responsible for the integrity of the competition by certifying that the necessary rules are complied with as well as ensuring that the tournament conditions offer a fully level playing field, proper matchmaking, and no cheating.

In exchange for these and other services, a fee or percentage of the skill-based gaming transaction would be assessed to each player or team. While amounts could vary, the fee would generally be no more than 10 percent of each player's or team's participation fee.

The chief advantage and one of the most desirable characteristics of peer-to-peer competition is the absence of risk. The tournament providers have no interest in whether any player wins or loses, unlike, in casino games in which the house has a built-in advantage in terms of odds, but has to manage the risk of high volatility in event outcomes, potentially losing significant sums if particular players manage to defy the odds on occasion.

Another benefit of peer-to-peer competition is that the interest of the tournament provider and the player(s) dovetail in that both seek frequent, diverse, and ample competition, allowing the tournament provider to exercise significant scalability.

The existing advantages and opportunities afforded to both players and tournament operators through peer-to-peer transactions are greatly enhanced by extending the concept to new forms of competition within esports.

These opportunities include:

- Identifying and including different demographics

- Generating new revenue streams

- Providing a framework for publishers and other interested parties to be involved in legal peerto-peer competition transactions.

\section{BACKGROUND}

For those not proficient in the activity, one generally held fallacy is that esports is an intermittent activity for kids who like to play video games. For those who professionally participate in esports nothing could be further from the truth. Professional and non-professional esports competitors engage in training regimens, develop their skills and abilities, ${ }^{1}$ and are considered athletes. ${ }^{2}$ Success in esports is determined by the skill of the player
Spectrum Gaming Group will serve as staff advisors to the Indian Gaming Esports Authority (IGEA)

Keywords: peer-to-peer; esports; sanctioning organization

DOI: 10.1089/glr2.2020.0024 (C) 2020 Mary Ann Liebert, Inc.
${ }^{1}$ What It Takes to Be a Professional eSports Athlete, Neurotracker (Aug. 14, 2018), https://www.neurotrackerx.com/post/what-it-takes-to-be-a-professionalesports-athlete (accessed Sept. 21, 2020).

${ }^{2}$ Id. See also Phil Birch and Edgar Chekera, Is an Esport Really a Sport?, Psychol. TodaY (Apr. 19, 2020), https://www.psychologytoday.com/us/blog/the-psychologyesports/202004/is-esport-really-sport (accessed Sept. 21, 2020). 
and not by random events or chance. Esports is about skill, not chance. ${ }^{3}$ As long as the game is deemed to be one of skill, players of electronic skill-based games wishing to engage in peer-topeer transactions for cash prizes based on their play are not subject to regulatory oversight and/or approval by state gambling regulators. ${ }^{4}$

The Georgia judiciary distinguished between participating in a game of skill and betting on a game of skill by drawing

a sharp distinction between a game of skill, baseball, and the wagering on such game of skill, which is a game of chance, stating "... [A] game of chance may be found under certain circumstances to be played between persons who wager or bet . . upon the outcome of a game although not actually participating in the game itself, which may or may not have been inaugurated primarily for the purpose of affording an opportunity for wagering or betting, even though the game is a game of skill, between the players who participated therein." (Grant v. State, 44 S.E.2d 513, 515 (Ga. Ct. App. 1947). Thus, case law still suggests that wagering on one's own personal skill in a game of skill in not prohibited gambling. Wagering on the outcome of a game of skill where you are not a participant, however, can be a violation of wagering or bookmaking laws. ${ }^{5}$

By contrast, gambling games are subject to state regulatory oversight and strict regulation. ${ }^{6}$ Gambling involves the wagering of something of value (usually money) on an event with an uncertain outcome, in the hope of winning something of value (usually money). In the U.S., states generally use one of three different tests to determine if an activity is considered gambling: the dominant factor test looks to whether or not the outcome of the game is based more on skill or chance; the material element test evaluates the element of chance in a game to ascertain if it is a material element; and the any chance test considers a game to be a gambling game if there is any randomness or chance in the outcome.

The random element of chance coupled with public policy priorities by state lawmakers to compel integrity in the wagering process is what necessitates strict regulation and oversight by gambling authorities. ${ }^{7}$

\section{SANCTIONING BODY}

A peer-to-peer esports sanctioning entity should be created to provide an organized forum in which stakeholders can discuss issues of mutual interest and agree on a set of integrity protocols which would be adhered to for peer-to-peer skill-based competition. The sanctioning body should also be a venue where tournament organizers, players, fans, observers, and others can report suspicious game play and other irregularities; the disciplinary authority for the reporting of potential disciplinary matters; and a resource for training, education, and establishing best practices.

\section{STAKEHOLDERS}

Stakeholders should include: ${ }^{8}$

- Game publishers

- Game developers

- Platform operators

- Event operators

- Leagues

- Teams

- Players

- Associations

- Clubs

- Streaming platforms

- Broadcasters

- Sponsors, and

- Payment processors
${ }^{3}$ Skill Gaming Legal Guide, WALTERS LAW Group, https://www.firstamendment. com/skill-gaming-legal-guide/ (accessed Sept. 21, 2020).

${ }^{4}$ Klein Moynihan Turco LLP, Games of Skill v. Games of Chance-The Legal Analysis, LeXology (Aug. 16, 2018), https://www.lexology.com/library/detail. aspx?g=0a16536c-4f6f-48ed-966f-a8d43b676f10 (accessed Sept. 22, 2020).

${ }^{5}$ Anthony N. Cabot and Keith C. Miller, The Law of Gambling and Regulated Gaming 20 (Carolina Academic Press, 2011).

${ }^{6}$ Nev. Rev. Stat. § 463.0129.

\section{${ }^{7} I d$.}

${ }^{8}$ See David J. Finch, Norm O'Reilly, Gashaw Abeza, Brad Clark, and David LegG,

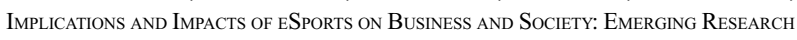
AND Opportunities (IGI Global, Oct. 2019); Ellen M. Zavian and Jim Schmitz, Genesis of an Industry: The Emerging Workforce and Regulations of Esports, ACC Docket (Apr. 4, 2019), https://www.accdocket.com/articles/emerging-workforceand-regulations-of-esports.cfm (accessed Sept. 21, 2020). 


\section{UNIFORM TERMINOLOGY}

Terms like peer-to-peer, microtransaction, competition, entry fees, cash tournaments, challenges, and contests should be defined with meanings that are utilized in a consistent way by the sanctioning body.

\section{UNIFORM STANDARDS}

Uniform standards for fundamental competition components, such as establishing a minimum age for participation in peer-to-peer microtransactions (should be at least 18 years old) and how competitions are conducted, would help establish the legitimacy of the sanctioning organization as well as the peer-to-peer microtransaction events.

In terms of competitive play, there tends to be a lack of information around how esports competitions are conducted. Some protocols for peer-to-peer competitions that should be established include:

1. A description of the event;

2. The manner in which peer-to-peer microtransactions can be conducted;

3. A description of any technology to be utilized during play;

4. A description of any technology necessary to determine the outcome of the event;

5. A description of how players will be evenly matched for competitive play;

6. A description of the integrity safeguards in place;

7. A description of how the event will be effectively supervised;

8. How the outcome of the event will be determined by a reliable and independent process;

9. How the outcome of the event will be verified;

10. A certification that the outcome of the event would be unlikely to be affected by any peer-to-peer microtransaction;

11. A certification that the event will be conducted in compliance with any applicable laws; and

12. Where the results will be published. ${ }^{9}$

\section{PLAYER REGISTRATION}

The sanctioning body could create a player registration portal. This would allow the sanctioning body to effectively interact with players interested in peer-topeer skill-based competitive play and to provide gamer education and resources. It would also enable a rating to be associated with players (similar to Uber and eBay). User ratings could help increase confidence levels among players. Other information such as inappropriate play, number of disputes, and dispute outcomes could be attached to player profiles by the sanctioning body. Such a registration would also allow for discredited players to be identified and could serve as a consumer protection tool. Data from the game publishers will be crucial in achieving these goals.

\section{TOURNAMENT PROCESS}

Tournament and competitive structures should be established and approved by the peer-to-peer esports sanctioning body. For example, are all peer-to-peer microtransactions to be single player? Could these transactions include multiple players or "teams" (groups of two or more players) that also compete against each other? There may be a benefit to a recognizable format for players that wish to compete for money against each other. Consistency will help to strengthen the legitimacy and integrity of this type of offering.

\section{DISPUTE RESOLUTION PROCESS}

A dispute resolution process should be created and administered through the sanctioning body. This will help ensure that there is a central body where players can file disputes and for those disputes to be handled fairly and in a timely, dependable manner.

Summaries of the substance of the outcomes of disputes could be located in a designated place on the sanctioning body's website for the public to access and for other players to review.

\section{GEOFENCING}

As games of skill have become more integrated with technology a new host of skill-based games has evolved. Not every state in the U.S. has approved 
electronic skill-based games. To prevent peer-to-peer microtransactions from taking place in states that prohibit or do not allow for electronic skill-based games, creators of peer-to-peer gaming platforms must not operate within these jurisdictions. The ability to prevent potential competitors from competing in jurisdictions that have failed to legalize skill-based peer-to-peer competitions for money via geofencing will be critical.

\section{U.S. SKILL-BASED CASH COMPETITIONS}

Though there is some conflicting information, primarily with regard to Vermont, below is a simplified overview of how various providers of skill-based, cash competitions hold themselves out.

\section{GameColony}

Players cannot participate in fee-based tournaments with prizes if they reside in the following states: Arizona, Arkansas, Delaware, Florida, Iowa, Illinois, Kentucky, Louisiana, Maryland, Missouri, New York, South Carolina, Nevada, Ohio, Washington, and Vermont. ${ }^{10}$

\section{Gamer Saloon}

Residents of Arizona may not play for cash prizes. ${ }^{11}$

\section{Skillz}

Skillz had an option to launch its platform across 46 states "but decided to go with the group of 37 states that all have adopted the same regulations. ${ }^{12}$ California, Massachusetts, New York, and Vermont are among the 37 states that have the same regulations. Skillz does not currently offer "real prize competitions" in nine states: Arizona, Arkansas, Connecticut, Delaware, Louisiana, Montana, South Carolina, South Dakota, and Tennessee. ${ }^{13}$

\section{CONCLUSION}

Since time immemorial, peer-to-peer skill-based competitions have been part of the competitive nature of humans. Today, however, with advancements in technology and the resulting interconnectivity of humanity through the Internet, this activity that once was limited to a physical setting has now transcended physical barriers. As such, it is the authors' opinion that an oversight and integrity authority for electronic peer-to-peer play be established in order to ensure integrity and fairness for the global audience that is already engaging in this activity without any protection and oversight.

\footnotetext{
${ }^{10}$ General Terms and Conditions, GAMERCOLONY.COM, https://gamecolony.com/ gtc99.html (accessed Sept. 22, 2020).

${ }^{11}$ Is GamerSaloon.com Legal?, GAMERSALOON, https://www.gamersaloon.com/ docs/faqs (accessed Sept. 22, 2020).
}

\footnotetext{
${ }^{12}$ Will Yakowicz, The Booming Business of Cash Prize Gaming, Inc.com, https:// www.inc.com/will-yakowicz/skillz-cash-prize-video-game-platform.html (accessed Sept. 22, 2020).

${ }^{13}$ The Legality of Skill Gaming, SKILLz, https://skillz.zendesk.com/hc/en-us/ articles/200620348-The-Legality-of-Skill-Gaming (accessed Sept. 22, 2020).
} 